\title{
Una propuesta inclusiva para la representación geométrica de poliedros con población en condición de discapacidad visual ${ }^{1}$
}

\author{
An inclusive approach to the geometric representation of \\ polyhedra with population condition visually impaired
}

Uma abordagem inclusiva para a representação geométrica dos poliedros com a condição da população deficiente visual

Recibido: mayo de 2013

Aceptado: agosto de 2013
Jenny Johanna Torres Rendon ${ }^{2}$

Yenny Roció Gaviria Fuentes ${ }^{3}$

\section{Resumen}

En este documento se presenta el diseño, ejecución y evaluación de una secuencia de actividades para la enseñanza de poliedros en un aula inclusiva con personas con limitación visual, implementada en el año 2012 en la Jornada Nocturna en el Colegio José Félix Restrepo I.E.D.

Palabras clave: Inclusión; poliedros; discapacidad visual; diversidad; necesidades especiales; sistemas de representación.

\begin{abstract}
This paper presents the design, implementation and evaluation of a sequence of activities for teaching in an inclusive classroom polyhedra with visually impaired people, implemented in 2012 on the Night Shift at José Félix Restrepo FDI
\end{abstract}

Keywords: Inclusion; polyhedra; visually impaired diversity; special needs representation systems.

\section{Resumo}

Este trabalho apresenta o projeto, implementação e avaliação de uma seqüência de atividades para o ensino em uma sala de aula inclusiva poliedros com as pessoas com deficiência visual, implementado em 2012 no turno da noite no José Félix Restrepo FDI

Palavras-Chave: Inclusão; poliedros; diversidade deficientes visuais; sistemas de representação de necessidades especiais.

\section{Artículo de investigación}

2 Universidad Distrital Francisco José de Caldas, Bogotá, Colombia. Contacto: annahojtore@gmail.com

3 Universidad Distrital Francisco José de Caldas, Bogotá, Colombia. Contacto: yengavi@gmail.com 


\section{¿Por qué realizar una secuencia en un aula inclusiva con personas en condición de dis- capacidad visual?}

Realizando una revisión a las políticas públicas, observamos que en la Ley General de Educación de 1994 se hace referencia a la inclusión educativa, sin tener mayores resultados ante la norma, debido a que en el contexto educativo actual no se evidencia dichas normatividades; por lo cual en el Plan Decenal (2006-2016) se proponen parámetros bajo los cuales se garantice la inclusión de la población con necesidades educativas especiales al sistema Educativo. Sin embargo observamos que en algunos colegios distritales se encuentran integradas personas en condición de discapacidad visual, pero el proceso inclusivo ha sido relegado a los tiflólogos en cada colegio, es decir sin integra a la comunidad educativa; motivo por el cual los docentes presentan temores (Rosich, 1996) al elaborar estrategias de aula que permitan realizar clases incluyentes donde se atiendan las necesidades de los estudiantes videntes e invidentes, ya que consideran no tener las herramientas suficientes y el tiempo en clase para atender los requerimientos de cada uno de los estudiantes.

\section{Marco de referencia conceptual}

Teniendo en cuenta la problemática, establecimos cuatro ejes temáticos sobre los cuales sustentar la secuencia de actividades para poder hacer un desarrollo geométrico de manera inclusiva con estudiantes con limitación visual:

- Marco Político, sustentado desde la Constitución política (1991), Ley General de Educación (1994), el Plan Decenal de educación (2006- 2016) y las Políticas Públicas para población vulnerable; se han implementado diferentes decretos que garanticen el ingreso de una educación incluyente para todos, sin embargo al observar el alto índice de deserción en los colegios de personas con necesidades educativas especiales, nos cuestiona el cómo garantizar algo que se supone debe cumplirse y conduce nuestra búsqueda al tener docentes comprometidos y creativos que permitan llevar un acercamiento del saber al estudiante.
- Marco Matemático, aquí citamos y tomamos como referencia para la elaboración de las actividades a Alsina (1999) desde la representación de espacios tridimensionales, a Guillen (1991) quien presenta algunas construcción de los poliedros regulares desde su estructura para observar y caracterización de aristas, vértices y caras. También Guillen (1991) presenta otra manera de caracterizar poliedros por medio de truncamiento de figuras, hallando ejes de simetría. Por último observamos a Godino para definir y caracterizar los poliedros y los polígonos obtenidos mediante el análisis de las caras de los poliedros.

- Marco Didáctico, para el análisis de las representaciones gráficas de personas con limitación visual Rosich (1996) menciona que se puede presentar alguna de las cuatro limitaciones: la primera limitación es inherente a las aptitudes del alumno: se habla de aptitudes hápticas y manipulativas, tanto de agudeza como de estrategias, posibilidades de estimación del desarrollo. Las representaciones en relieve exigen por parte del observador o autor ciego un esfuerzo perceptivo notable. La percepción háptica comprende ejercicios musculares $\mathrm{y}$ manipulativos, percepciones cinestésicas, reelaboración de los datos elementales obtenidos. La configuración fina es también global, unitaria, sintética; como en el caso de la percepción visual. La adaptación a las características de la percepción háptica, según la autora, refiere al relieve o intensidad suficiente del trazo, dimensiones del conjunto no superiores al ámbito bimanual, separación discriminante entre líneas o puntos, esquema corporal adecuado, posición exploratoria preferente-proximidad y coincidencia entre eje de la figura y plano corporal antero-posterior. La segunda limitación, referenciada por Rosich (1996) está relacionada con las posibilidades intrínsecas del material: mediante representaciones en las que se emplee variedad de trazos y margen diferenciando sus grosores, los cuales representarán los colores y brillos de las imágenes $\mathrm{u}$ objetos que se deseen representar. La tercera limitación es consecuencia de la complejidad de la representación, lo que conlleva a que en 
las actividades de matematización puedan surgir representaciones complejas, no tanto por la diversidad de enfoques como por la de líneas o elementos intervinientes, es el caso de algunas demostraciones geométricas, composición de rotaciones y simetrías.

- Marco metodológico, para la realización de las actividades tuvimos en cuenta los Estándares Básicos para Matemáticas (MEN, 2007) para ciclo tres, tomando exclusivamente a los que hacen referencia a Poliedros y Polígonos. Para la evaluación de las sesiones, tuvimos en cuenta el modelo Van Hiele (Sorberán, 1989) mediante los niveles y fases nos permite establecer una categorización de los trabajos realizados por los estudiantes, posibilitando un análisis de la información recolectada.

\section{Objetivo general de la propuesta}

Potenciar procesos de reconocimiento del espacio bidimensional y tridimensional a partir de la geometría poligonal y poliédrica en un aula inclusiva para estudiantes invidentes, mediante el diseño, aplicación y evaluación de una secuencia de actividades.

\section{Metodología}

La metodología para la implementación de la propuesta es diseñar una secuencia de actividades y aplicarla con el fin de potenciar el reconocimiento de espacios tridimensionales y bidimensionales a partir de la manipulación de poliedros. Dicha secuencia se construyó teniendo en cuenta dos ejes: el primero tiene como fundamento el marco legal mediante la revisión de los estándares curriculares para matemáticas (MEN, 2007) tomando los correspondientes a geometría (poliedros y polígonos), el segundo hace referencia a las fases de aprendizaje que propone Van Hile (1989) para el aprendizaje de poliedros. Al hacer un entre cruzamiento entre estos dos ejes tenemos como resultado las actividades de la secuencia, como se muestra a continuación:

Tabla 1

\begin{tabular}{|c|c|c|c|c|c|c|}
\hline $\begin{array}{l}\text { ESTANDARES } \\
\text { BÁSICOS PARA } \\
\text { MATEMATICAS }\end{array}$ & NIVELES & $\begin{array}{l}\text { FASE 1 } \\
\text { ENCUESTA } \\
\text { INFORMACIÓN }\end{array}$ & $\begin{array}{l}\text { FASE } 2 \\
\text { ORIENTACIÓN } \\
\text { DIRIGIDA }\end{array}$ & $\begin{array}{l}\text { FASE } 3 \\
\text { EXPLICACIÓ } \\
\mathrm{N}\end{array}$ & $\begin{array}{l}\text { FASE 4 } \\
\text { ORIENTACIÓ } \\
\text { N LIBRE } \\
\end{array}$ & $\begin{array}{l}\text { FASE } 5 \\
\text { INTEGRACIÓN }\end{array}$ \\
\hline $\begin{array}{l}\text { Represento } \\
\text { objetos } \\
\text { tridimensionale } \\
\text { s desde } \\
\text { diferentes } \\
\text { posiciones y } \\
\text { vistas. }\end{array}$ & $\begin{array}{l}\text { NIVELO } \\
\text { VISUALIZACIÓN }\end{array}$ & $\begin{array}{l}\text { Los estudiantes dibujan } \\
\text { figuras tridimensionales. } \\
\text { Hacen uso de } \\
\text { instrumentos } \\
\text { geométricos. }\end{array}$ & $\begin{array}{l}\text { Los estudiantes } \\
\text { construyen los } \\
\text { poliedros (pitillos) } \\
\text { y lo dibujan. } \\
\text { Hacen uso de } \\
\text { instrumentos } \\
\text { geométricos para } \\
\text { representar. }\end{array}$ & $\begin{array}{l}\text { Comparanlas } \\
\text { representacion } \\
\text { es. } \\
\text { Comunicación } \\
\text { matemática. }\end{array}$ & $\begin{array}{l}\text { Representacio } \\
\text { nes y } \\
\text { construcción } \\
\text { de dodecaedro } \\
\text { y el icosaedro. } \\
\text { Modelar. }\end{array}$ & $\begin{array}{l}\text { Características } \\
\text { de cada } \\
\text { poliedro. }\end{array}$ \\
\hline $\begin{array}{l}\text { Identifico y } \\
\text { describo figuras } \\
\text { y cuerpos } \\
\text { generados por } \\
\text { cortes rectosy } \\
\text { transversales } \\
\text { de objetos } \\
\text { tridimensionale } \\
\text { s. }\end{array}$ & $\begin{array}{l}\text { NIVEL 1 } \\
\text { ANÁLISIS }\end{array}$ & $\begin{array}{l}\text { Representar Posibles } \\
\text { cortes en el cubo para } \\
\text { llegar al resto de sólidos. }\end{array}$ & $\begin{array}{l}\text { Realiza los cortes } \\
\text { en la figura }\end{array}$ & $\begin{array}{l}\text { Observandosi } \\
\text { la } \\
\text { representación } \\
\text { previa es } \\
\text { correctay } \\
\text { establecer } \\
\text { coincidencias } \\
\text { con los cortes } \\
\text { realizados. } \\
\text { Comunicación } \\
\text { matemática. }\end{array}$ & $\begin{array}{l}\text { Cortes para el } \\
\text { dodecaedroe } \\
\text { icosaedro. }\end{array}$ & $\begin{array}{l}\text { Explicitación de } \\
\text { simetrías. }\end{array}$ \\
\hline $\begin{array}{l}\text { Clasifico } \\
\text { polígonos en } \\
\text { relación con sus } \\
\text { propiedades. }\end{array}$ & $\begin{array}{l}\text { NIVEL } 2 \\
\text { DEDUCCIÓN } \\
\text { INFORMAL } \\
\text { (ORDENACIÓN) }\end{array}$ & $\begin{array}{l}\text { Grafica y describe } \\
\text { características (lados, } \\
\text { vértices, ángulos) de las } \\
\text { caras de los poliedros } \\
\text { trabajados. }\end{array}$ & $\begin{array}{l}\text { De acuerdo a las } \\
\text { características } \\
\text { encontradas } \\
\text { clasifica según } \\
\text { parámetros } \\
\text { establecidos. } \\
\end{array}$ & $\begin{array}{l}\text { Exposición de } \\
\text { parámetros } \\
\text { encontrados } \\
\text { para realizar la } \\
\text { clasificación. }\end{array}$ & $\begin{array}{l}\text { Compara áreas } \\
\text { y perímetros } \\
\text { de las caras de } \\
\text { las figuras } \\
\text { trabajadas } \\
\text { (polígonos). }\end{array}$ & $\begin{array}{l}\text { Caracterización } \\
\text { de poliedros, } \\
\text { polígonos y } \\
\text { diferencia entre } \\
\text { áreay } \\
\text { perímetro. }\end{array}$ \\
\hline
\end{tabular}

Fuente: Elaboración propia 
La secuencia consta de seis actividades tituladas: "Dibujando Mi Espacio, Construyendo El Universo, Transformando Figuras, De La Tierra Al Agua y El Universo, En Busca De Los Elementos y El Universo, Los Sólidos En Perimerandia”

\section{Conclusiones}

Por medio de la elaboración e implementación de los solidos platónicos Se potenció el reconocimiento del espacio bidimensional y tridimensional en los estudiantes de un aula inclusiva con estudiantes en condición de discapacidad visual, a partir del diseño, ejecución y evaluación de la secuencia de actividades; creando así un ambiente de inclusión en el cual los estudiantes videntes y en condición de discapacidad visual, generaban una interacción al momento de realizar las tareas propuestas.

Para el diseño fue de gran importancia la realización de una revisión teórica que nos permitió visualizar la ruta de aprendizaje seguida por los estudiantes para lograr un acercamiento de lo tridimensional a lo bidimensional de los poliedros regulares.

Se evidenció por medio de la interacción de los estudiantes acciones de inclusión al momento en que los estudiantes videntes mostraran interés en el trabajo realizado por el estudiante en condición de discapacidad visual, proporcionando y atendiendo las necesidades del estudiante en cuanto a los materiales y dudas. Sin embargo se presentan acciones de exclusión en el desarrollo de trabajos grupales. La inclusión vista desde las destrezas de cada uno de los estudiantes de los grupos en la agilidad para el desarrollo de las actividades, mostró cómo podían ayudar a sus pares solucionando dudas o interviniendo en discusiones grupales.

Se evidenció que la adaptación de material es un punto estratégico para la ejecución y diseño de la secuencia de actividades, pues permite que los estudiantes videntes y en condición de discapacidad visual tengan un mayor acercamiento a los conceptos involucrados en el trabajo con poliedros y polígonos.
Algunos elementos a tener en cuenta:

- Los estudiantes tienen en cuenta conocimientos o experiencias previas en el momento de realizar dibujos, es notorio el proceso de cada uno cuando se les pide representar algunos objetos ya que pudimos observar en la actividad número uno que cada representación tiene características particulares que van siendo más detalladas y brindan más información de acuerdo al histórico del estudiante. Con respecto a los dibujos realizados por el estudiante invidente, la primera clase él plasmo en detalle lo que recordaba acerca de objetos tridimensionales, sin embargo la segunda sesión fue de mayor dificultad para él ya que tenía que representar objetos que no eran tan cotidianos; esto permitió ir creando un ambiente inclusivo en el cual tanto los estudiantes videntes como los invidentes pudieran cuestionarse bajo un mismo objetivo y teniendo como excusa el cómo poder representar y construir poliedros regulares.

- La intermitencia académica por parte de los estudiantes pude ser un factor que obstruya sus procesos cognitivos, ya que al ausentarse de clase es posible que el estudiante no comprenda qué se está trabajando y ni bajo qué objetivo; esto lo observamos tanto con estudiantes videntes como invidentes, ya que como se aprecia en el análisis uno de los estudiantes invidentes no asistió a la mayoría de actividades, teniendo como consecuencia una práctica en la construcción más no en la representación de poliedros, particularmente se puede evidenciar esto en la actividad de truncamiento de las figuras, ya que primero se hizo una imagen mental de la figura mediante el dibujo y posteriormente se construyó, más no se buscó modelarla.

- Los estudiantes videntes en términos de representación pueden presentar las mismas dificultades que un estudiante en condición de discapacidad visual, teniendo en cuenta la complejidad de la figura que se desee realizar. 
Es de resaltar la exigencia que debe tener un docente al estar trabajando en un aula inclusiva, pensar el material que permita potenciar el pensamiento crítico de los estudiantes a nivel general, no es estrictamente necesario tener elementos específicos para cierto tipo de población, se debe pensar en los ajustes que se podrían realizar para que el material sea inclusivo. Además es importante el lenguaje utilizado por el docente en el desarrollo de las temáticas ya que se tiende a caer en muletillas o términos no comprensibles para los estudiantes, también es necesario el uso de lenguaje matemático.

\section{Referencias}

Alsina, C. (1999). Invitación a la Didáctica de la Geometría. Madrid: Síntesis
Constitución política de Colombia (1991)

Guillén G. (1991). Poliedros. Editorial síntesis, Madrid, España.

Ley general de educación (1994)

Ministerio de Educación Nacional (2007).

Estándares básicos de competencias en matemáticas. MEN. Bogotá.

Rosich, N., Núñez, J., Fernández, J. (1996). Matemática y deficiencia sensorial. Editorial Síntesis Madrid, España. 